\title{
Prescribing Practice of Antidepressant Drugs at Outpatient Department of a Tertiary Care Teaching Hospital in Bangladesh
}

\author{
Md. Rabiul Islam ${ }^{*}$, Ayeshi Shafique ${ }^{2}$ \\ ${ }^{1}$ Department of Clinical Pharmacy and Pharmacology, Faculty of Pharmacy, University of Dhaka, Dhaka, Bangladesh \\ ${ }^{2}$ Department of Pharmacy, Jahangirnagar University, Savar, Dhaka, Bangladesh \\ Email: ^robi.ayaan@gmail.com
}

How to cite this paper: Islam, Md. R., \& Shafique, A. (2017). Prescribing Practice of Antidepressant Drugs at Outpatient Department of a Tertiary Care Teaching Hospital in Bangladesh. Open Journal of Depression, 6, 14-23.

https://doi.org/10.4236/ojd.2017.61002

Received: December 27, 2016

Accepted: February 6, 2017

Published: February 9, 2017

Copyright $\odot 2017$ by authors and Scientific Research Publishing Inc. This work is licensed under the Creative Commons Attribution International License (CC BY 4.0).

http://creativecommons.org/licenses/by/4.0/

\begin{abstract}
Objectives: In Bangladesh $16.05 \%$ of adult population suffer from psychiatric illness of which $28.7 \%$ suffer from Major Depressive Disorder (MDD). Although antidepressants are the recommended first-line pharmacological treatments for MDD, their prescribing patterns have not been studied in Bangladesh. This study investigates antidepressant prescription patterns at the outpatient psychiatry department of Bangabandhu Sheikh Mujib Medical University (BSMMU), Bangladesh. Material and methods: A retrospective review of the case notes of psychiatry outpatients at BSMMU was carried out between April 2014 and December 2015. A total of 281 MDD patients (aged 18 to 60 years) were randomly recruited. Relevant information was obtained by collection of prescription details from the patients or their relatives by face to face interview. Results: The average number of drugs prescribed per prescription was 2.4. Antidepressants were prescribed in $83.6 \%$ (235) encounters that constituted $76.5 \%$ (235) of the total number of prescribed drugs. About $82.5 \%$ (232) antidepressants were prescribed in combination with psychotherapy. Nearly $50 \%$ (141) of prescribed antidepressants were selective serotonin reuptake inhibitors (SSRIs). Among all antidepressant classes, escitalopram (22.1\%), mirtazapine (21.4\%), and sertraline (16.4\%) were the leading drug prescribed. Lithium was prescribed to $4.6 \%$ (13) of patients. Conclusion: Novel antidepressant (SSRIs and SNRIs) drugs were prescribed more compared to traditional drugs (TCAs and TeCAs). In many cases, antidepressants were prescribed in combination with psychotherapy which is good practice to treat depression. It is expected that this investigation will be helpful to treat MDD patients with more precision in drug assortment and benefit to the patients.
\end{abstract}

\section{Keywords}

Prescribing Practice, Antidepressant Drugs, Outpatient Department, Bangladesh 


\section{Introduction}

Major Depressive Disorder (MDD) is a mental disorder described by a persistent and pervasive low mood which is attended by low self-esteem and loss of pleasure or interest in daily events that unfavorably disturbs a person's family, effort and personal life (Wakefield et al., 2007). Lifetime prevalence of depression in USA is, $12 \%$ more in men and $20 \%$ more in women compare to universe (Kessler et al., 2003). Sometimes, severe depression is termed as melancholia or vital depression in a much narrower way (Van Praag, 1987). There is an overlap of some pathogenetic mechanisms between major depression and manic episode. A distinct illness termed as bipolar disorder sometimes may be a history of mania (Belmaker, 2004). In USA approximately 3.4\% of people suffering from major depression are committed to suicide. Conversely, $60 \%$ of the people who are committed to suicide had depression or another mood disorder (Barlow \& Durand, 2005). Approximately $4.3 \%$ population suffers from MDD globally (Vos et al., 2012). Twelve-month prevalence of MDD is $4.9 \%$ in men and $8.6 \%$ in women while lifetime prevalence is $13.2 \%$ in men compared with $20.2 \%$ in women globally (Rustad et al., 2013). Interestingly, lifetime occurrence is $3 \%$ in Japan and $17 \%$ in USA, indicating significant geographical and/or cultural variation (Andrade et al., 2003). Prevalence of MDD for a year-long period is 3\% - 5\% in males and $8 \%-10 \%$ in females among North Americans (Murphy et al., 2000). In Bangladesh prevalence of MDD is $4.6 \%$ and among all psychiatric patients the percentage is 28.7. Both mild to moderate and severe depression are more common in females and among singles (Firoz et al., 2006). Different studies reveal that the chance of having major depression is twice in women than men but the reason is not clear and which factors are responsible for this are not known either (Kuehner, 2003). People generally experience their first depressive episode during the fourth decade of life and there may be a second smaller peak at the age 50 to 60 years. Increased chance of depressive episodes associated with some states such as Parkinson's disease, stroke, or multiple sclerosis and throughout the first year after delivery (Rickards, 2005). Urban populations suffer from depressive disorders more than the rural people.

According to biopsychosocial model, biological, psychological and social factors show a significant role in emerging depression (Fundamentals of mental health and mental illness by US Department of Health and Human Services (1999). The preexisting vulnerability can be either genetic (Caspi et al., 2003; Haeffel et al., 2008), implying an interaction between nature and nurture or schematic, resulting from childhood views of the world (Slavich, 2004). Depressive episode may also be due to damage of cerebellum as is seen in cerebellar cognitive affective syndrome (Konarski et al., 2005; Schmahmann et al., 2007; Schmahmann, 2004). Heritability of depression has been estimated in a Swedish study where they explained that the severity of depression is linked with the degree of genetic variation (Kendler et al., 2006). Long-term drug use or abuse and withdrawal from certain sedative or hypnotic drugs are generally linked with major depression (Ashton, 2002; Schuckit et al., 1997). MDD is a disease that is 
usually manageable; among people who seek treatment $80 \%$ find that psychotherapy and medications are effective for them. Patients normally start to get significant benefits from treatment within 4 - 6 weeks after initiation (Diagnostic and Statistical Manual for Mental Disorders, DSM-5, $5^{\text {th }}$ Ed.). Although psychiatric medication is the most often prescribed therapy for major depression (Carson, 2000) psychotherapy alone or in combination with medication is a very effective option as well (Callaway, 1972). Antidepressant medications do not consistently demonstrate their superiority over placebo or their benefit in treating depression is little. Similarly, substantial superiority over no-treatment has not been demonstrated by psychotherapy. Combination of both psychotherapy and antidepressants can provide a slight advantage. Once MDD is accurately diagnosed, any treatment option is not generally known to be more effective than getting depressed patients involved in an active therapeutic program (Khan et al., 2012). For patients who are under 18 years of age, psychotherapy is the treatment of choice. Parents should also be considered for psychotherapy parallel with their child who suffers from depression due to substance abuse for better treatment outcomes (NICE, 2005).

\section{Material and Methods}

A retrospective review of the case notes of outpatients was carried out between April 2014 and December 2015. A total of 281 MDD patients, age ranging from 18 to 60 years, were randomly recruited from the outpatient Department of Psychiatry, Bangabandhu Sheikh Mujib Medical University (BSMMU) Hospital, Bangladesh. Patients under the age of 18 , above the age of 60 or those having a severe general medical condition were not included in the study. A specialist psychiatrist conducted the diagnosis and interview of the patients based on DSM-V (2013). The data were taken by collection of prescription details from the patients or their relatives by face to face interview with them. The study subjects were briefed about the purpose of the study and written consent was taken from each of them. Each of the subjects filled up a questionnaire form which contains personal information, socio-economic data, history of illness, family history and other demographic and medical information. The forms of the patients who had no formal education were filled out with the help of their primary care givers. Study protocol and volunteer consent form was approved by the ethical review committee of Department of Psychiatry, BSMMU. Statistical analysis was performed using the statistical software package SPSS, version 23.0 (SPSS Inc., Chicago, IL). Descriptive data has been given as frequencies and percentages.

\section{Results}

The socio-demographic characteristics of the respondents are shown in Table 1. Respondents had a mean age of 31.24 years (SD \pm 13.46 ) and approximately $60 \%$ (169) of respondents were found within an age range of 25 - 44 years. Among all respondents, $41 \%$ (115) were male and 59\% (166) were female. Roughly $33 \%$ 
Table 1. Socio-demographic characteristics of the respondents.

\begin{tabular}{|c|c|c|c|c|}
\hline \multirow{2}{*}{\multicolumn{2}{|c|}{ Parameters }} & \multicolumn{3}{|c|}{ Respondents $(\mathrm{n}=281)$} \\
\hline & & $\mathrm{n}$ & $\%$ & Mean \pm SD \\
\hline \multirow{5}{*}{ Age in years } & $18-24$ & 30 & 11 & \multirow{5}{*}{$31.24 \pm 13.46$} \\
\hline & $25-34$ & 98 & 35 & \\
\hline & & & & \\
\hline & $35-44$ & 101 & 36 & \\
\hline & $45-60$ & 52 & 19 & \\
\hline \multirow[b]{2}{*}{ Gender } & Male & 114 & 41 & \multirow{7}{*}{ n.a } \\
\hline & Female & 167 & 59 & \\
\hline \multirow{5}{*}{ Education } & Illiterate & 64 & 23 & \\
\hline & Can read only & 32 & 11 & \\
\hline & Secondary & 44 & 16 & \\
\hline & Higher secondary & 68 & 24 & \\
\hline & Graduate and above & 73 & 26 & \\
\hline \multirow{5}{*}{ Occupation } & Service & 62 & 22 & \multirow{5}{*}{ n.a } \\
\hline & Business & 54 & 19 & \\
\hline & Student & 34 & 12 & \\
\hline & Others & 57 & 20 & \\
\hline & Jobless & 74 & 26 & \\
\hline \multirow{4}{*}{$\begin{array}{l}\text { Monthly income } \\
\text { in KBDT }\end{array}$} & Below 10 & 92 & 33 & \multirow{4}{*}{$18.42 \pm 13.35$} \\
\hline & $10-25$ & 87 & 31 & \\
\hline & $26-40$ & 74 & 26 & \\
\hline & Above 40 & 28 & 10 & \\
\hline
\end{tabular}

respondents were found to be below secondary level of education, whereas $16 \%$, $24 \%$ and $26 \%$ respondents had education equivalent to secondary, higher secondary and graduation or higher respectively. Among all respondents $26 \%$ were jobless. Approximately $64 \%$ respondents had family income below 25 KBDT (Kilo Bangladeshi Taka) and their mean income was 18.42 KBDT (SD \pm 13.35 ).

The average number of drugs prescribed per encounter was 2.4. In $74.5 \%$ (209) prescriptions, the range of drugs prescribed varied from 1 to 6 . There was not a single encounter where no drug was prescribed. Antidepressants were prescribed in $83.6 \%$ (235) of the prescriptions and these constituted $76.5 \%$ (215) of the total number of prescribed drugs. About $82.5 \%$ (232) antidepressants were prescribed in combination with psychotherapy. Approximately $20 \%$ prescriptions were written for psychotherapy with other drugs where antidepressants were not mentioned. As shown in Figure 1 about 50\% (141) of the cases, selective serotonin reuptake inhibitors (SSRIs) were prescribed as antidepressant drugs, followed by tetracyclic antidepressants (TeCAs), tricyclic antidepressants (TCAs) and serotonin norepinephrine reuptake inhibitors (SNRIs). Among all 


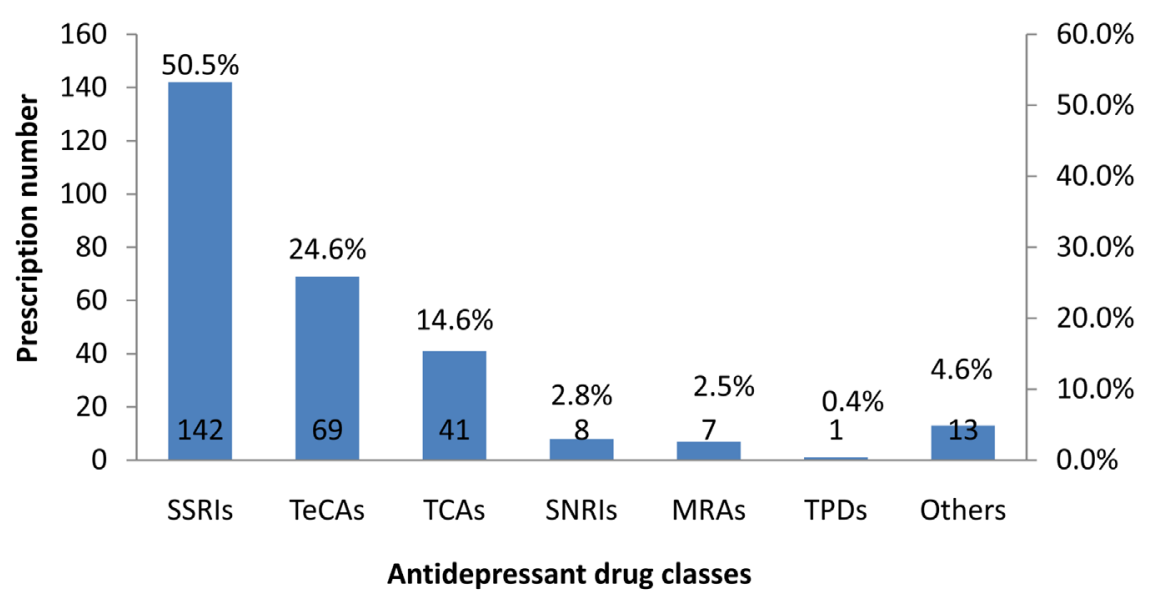

Figure 1. Antidepressant drug classes used at outpatient department of a tertiary teaching hospital in Bangladesh.

antidepressant classes, Escitalopram (22.1\%), Mirtazapine (21.4\%), and Sertraline (16.4\%) were the leading prescribed medications (Figure 2). Escitalopram (44\%), Sertraline (32\%), and Fluoxetine (19\%) were the top serotonin norepinephrine reuptake inhibitors prescribed (Figure 3). About 56\% (23) of tricyclic antidepressant prescriptions were found for amitriptyline (Figure 4). Lithium was also prescribed in $4.6 \%$ (13) cases to treat depression.

\section{Discussion}

The current study was conducted to explore the antidepressant drug prescribing practice at outpatient department of a tertiary care teaching hospital in Bangladesh. The main findings of this study were comparable with similar studies in some other countries in Asia. The main findings revealed that people generally develop depression at their third and fourth decades of life. Similar result was reported in another study e.g. people generally experience their first depressive episode during forth decade of life and there may have a second smaller peak at the age 50 to 60 years (Rickards, 2005). The prevalence was more among females than males which is supported by a study where reported that lifetime prevalence of depression in USA is more than $12 \%$ in men and $20 \%$ in women (Kessler et al., 2003). Both mild to moderate and severe depression are more common in females and among singles (Firoz et al., 2006). Different studies reveal that the chance of having major depression is twice in women than men but the reason is not clear and which factors are responsible for this are not known (Kuehner, 2003). As per our study, we found there was a tendency to develop depression among illiterate and highly educated people. The figures in this study tended to fall in line with figures reported by other similar studies.

However psychiatric medication is the most often prescribed therapy for major depression (Carson, 2000) but psychotherapy either alone or in combination with medication is very effective option (Callaway, 1972). Approximately $20 \%$ prescriptions were written for psychotherapy with other drugs where antidepressants were not mentioned. In this current study about $84 \%$ patients were 


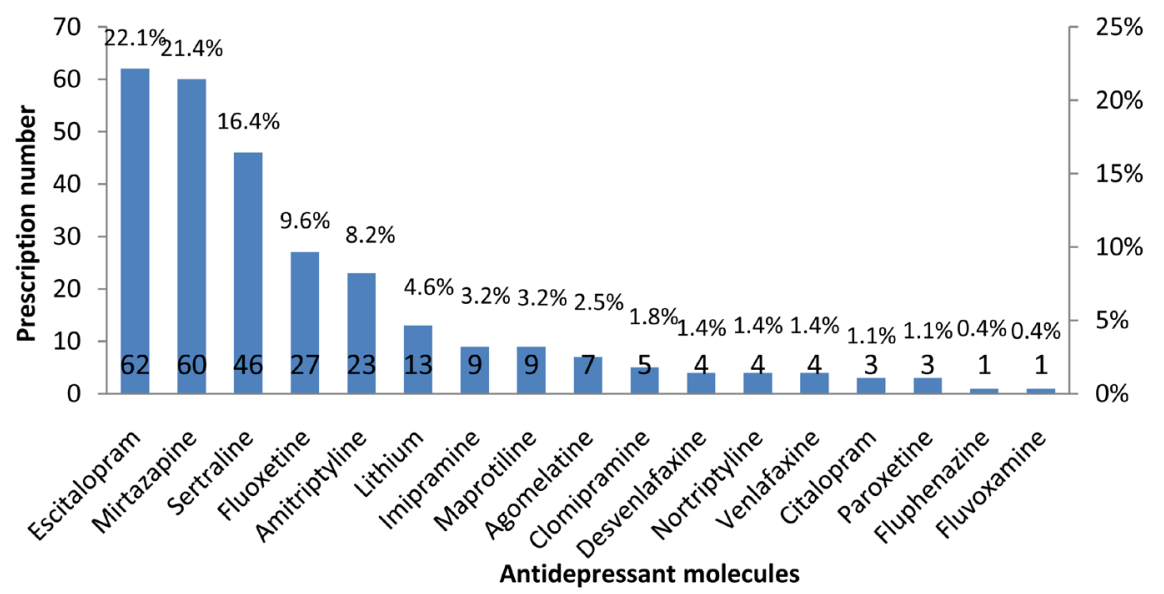

Figure 2. The most frequently prescribed antidepressant molecules at outpatient department of a tertiary teaching hospital in Bangladesh.

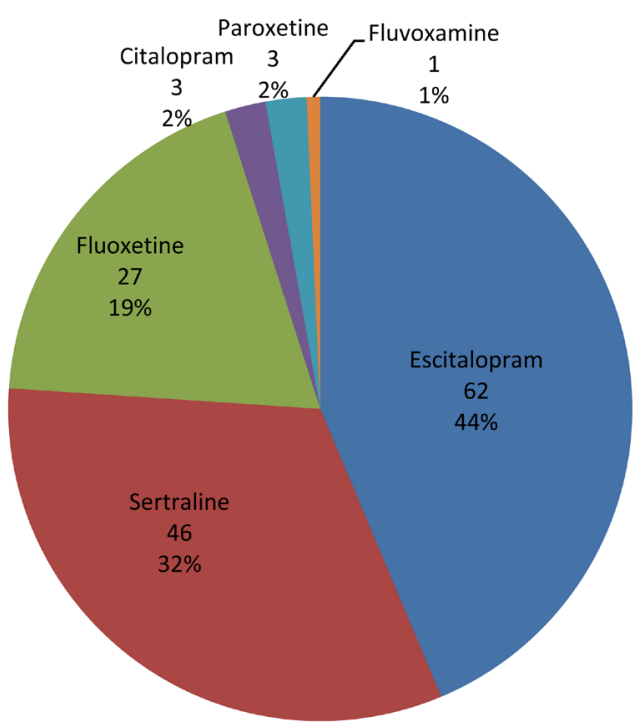

Figure 3. Distribution of selective serotonin reuptake inhibitors (SSRIs) used for major depression.

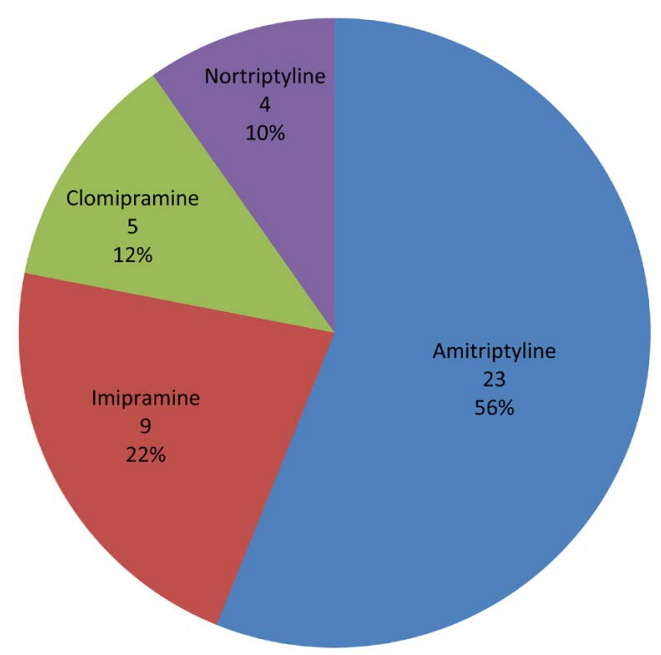

Figure 4. Distribution of tricyclic antidepressants (TCAs) used for major depression. 
offered treatment with an antidepressant, of which SSRIs were the most commonly prescribed (50\%). This is in keeping with the results of studies done in Asia (Zhang et al., 2013; Sim et al., 2007; Bae et al., 2001), the United States (Ivanova et al., 2011) and Europe (Bauer et al., 2008). SSRIs are effective in the treatment of MDD. It is demonstrated in many studies that the efficacy of SSRIs is superior to other antidepressant medications, mainly Tetracyclic Atidepressant (TCAs) (Anderson, 2000; Arroll et al., 2009; Cipriani et al., 2005). Result from the current study shows that new antidepressant drugs (SSRIs, SNRIs, NRIs, etc.) account for $53.4 \%$ of all antidepressant prescriptions compared to traditional drugs (TCAs and TeCAs) which make up 39.1\% of the total prescriptions. Figure in this study is lower than the $77 \%$ figure, though comparable to figures from Australia and England (Moore et al., 2009), 58\% in Australia (Hollingworth et al., 2010) and 50\% in England (Uchida et al., 2007). The current study revealed that, among all antidepressant drug classes, Escitalopram (22.1\%), Mirtazapine (21.4\%), and Sertraline (16.4\%) were the leading prescribed medications. Another study in India where the number of patients receiving Escitalopram, Sertraline, Paroxetine and Fluoxetine was 36.54\%, 3.78\%, 7.37\%, and 6.73\%, respectively (Adarsh et al., 2016). Escitalopram (44\%), Sertraline (32\%), and Fluoxetine (19\%) were the top serotonin norepinephrine reuptake inhibitors prescribed at the outpatient department of this tertiary hospital in Bangladesh. This finding is very much similar to another study report in India where 56\% prescription for Sertraline and 30\%, 10\%, and 2\% for Escitalopram, Fluoxetine, and Fluoxamine, respectively (Memon \& Patel, 2013). Lithium prescription (4.6\%) for depression was found as new treatment approach in a tertiary care hospital setup.

The limitation of our study was we did not investigate whether the patients have any special external reason for depression which can be solved only by psychotherapy. Therefore, further study may be needed to determine whether social conditions influence on the prescribing habit of antidepressants drugs. Another drawback of our present study was we took small number of samples from single center. So, if we want to produce more and more valued conclusion for our present study, we need to be carried out this study over large number of samples from different regional part of Bangladesh. In spite of these limitations, we hope our study will play an important role understand the prescription pattern of antidepressants in Bangladesh.

\section{Conclusion}

The results of the present study showed that novel antidepressant (SSRIs and SNRIs) drugs were prescribed more compared to traditional drugs (TCAs and TeCAs). More than eighty percent antidepressants were prescribed in combination with psychotherapy as psychotherapy alone or in combination with medication is a very effective option to treat major depression. It is expected that this investigation will be helpful for the management of MDD with more perfection in drug assortment and benefit to the patients. 


\section{Acknowledgements}

The authors are thankful to all the staffs of outpatient Department of Psychiatry, Bangabandhu Sheikh Mujib Medical University, and the nearby pharmacies for their precious time, technical and administrative support for the collection of prescription data throughout the study period. The authors are also thankful to all the patients and their caregivers for their cooperation in this study.

\section{Conflict of Interest}

The authors declare that there is no conflict of interests regarding the publication of this article.

\section{References}

Adarsh, T., Ajit, A., Avinash, D., Dipesh, B., Nilesh, S., Roy, A. K., Grover, S., Trivedi, J. K., \& Shinfuku, N. (2016). Prescription Pattern of Antidepressants in Five Tertiary Care Psychiatric Centres of India. Indian Journal of Medical Research, 143, 507-513. https://doi.org/10.4103/0971-5916.184289

Anderson, I. M. (2000). Selective Serotonin Reuptake Inhibitors versus Tricyclic Antidepressants: A Meta-Analysis of Efficacy and Tolerability. Journal of Affective Disorders, 58, 19-36. https://doi.org/10.1016/S0165-0327(99)00092-0

Andrade, L., Caraveo-Anduaga, J. J., Berglund, P., Bijl, R. V., De Graaf, R. et al. (2003). The Epidemiology of Major Depressive Episodes: Results from the International Consortium of Psychiatric Epidemiology (ICPE) Surveys. International Journal of Methods in Psychiatric Research, 12, 3-21. https://doi.org/10.1002/mpr.138

Arroll, B., Elley, C. R., Fishman, T., Goodyear-Smith, F. A., Kenealy, T., Blashki, G., Kerse, N., \& Macgillivray, S. (2009). Antidepressants versus Placebo for Depression in Primary Care. The Cochrane Database of Systematic Reviews, 8, CD007954. https://doi.org/10.1002/14651858.CD007954

Ashton, H. (2002). Benzodiazepine Abuse, Drugs and Dependence (pp. 197-212). London: Routledge and New York, NY: Harwood Academic Publishers.

Bae, K. Y., Kim, S. W., Kim, J. M., Shin, I. S., Yoon, J. S., \& Jung, S. W. (2001). Antidepressant Prescribing Patterns in Korea: Results from the Clinical Research Center for Depression Study. Psychiatry Investigation, 8, 234-244. https://doi.org/10.4306/pi.2011.8.3.234

Barlow, D. H., \& Durand, V. M. (2005). Abnormal Psychology. In C. A. Belmont (Ed.), An Integrative Approach (5th ed.). USA: Thomson Wadsworth.

Bauer, M., Monz, B. U., Montejo, A. L., Quail, D., Dantchev, N., \& Demyttenaere, K. (2008). Prescribing Patterns of Antidepressants in Europe: Results from the Factors Influencing Depression Endpoints Research (FINDER) Study. European Psychiatry, 23, 66-73. https://doi.org/10.1016/j.eurpsy.2007.11.001

Belmaker, R. H. (2004). Bipolar Disorder. The New England Journal of Medicine, 351, 476-486. https://doi.org/10.1056/NEJMra035354

Callaway, W. (1972). Merck Manual of Diagnosis and Therapy. JAMA, 222, 213. https://doi.org/10.1001/jama.1972.03210020059024

Carson, V. B. (2000). Mental Health Nursing: The Nurse-Patient Journey (p. 423). Philadelphia, PA and London: W.B. Saunders.

Caspi, A., Sugden, K., Moffitt, T. E., Taylor, A., Craig, I. W., Harrington, H., McClay, J., Mill, J., Martin, J., Braithwaite, A., \& Poulton, R. (2003). Influence of Life Stress on 
Depression: Moderation by a Polymorphism in the 5-HTT Gene. Science, 301, 386-389. https://doi.org/10.1126/science.1083968

Cipriani, A., Brambilla, P., Furukawa, T., Geddes, J., Gregis, M., Hotopf, M., Malvini, L., \& Barbui, C. (2005). Fluoxetine versus Other Types of Pharmacotherapy for Depression. The Cochrane Database of Systematic Reviews, 19, CD004185. https://doi.org/10.1002/14651858.CD004185.pub2

DSM-5 (2013). Diagnostic and Statistical Manual for Mental Disorders $\left(5^{\text {th }}\right.$ ed.). American Psychiatric Association.

Firoz, A. H. M., Karim, M. E., Alam, M. F., Rahman, A. H. M., Zaman, M. N., \& Chandra, V. (2006). Community Based Multicentric Service Oriented Research on Mental Illness with focus on Prevalence, Medical Care, Awareness and Attitude towards Mental Illness in Bangladesh. Bangladesh Journal of Psychiatry, 20, 9-32.

Haeffel, G. J., Getchell, M., Koposov, R. A., Yrigollen, C. M., Deyoung, C. G., Klinteberg, B. A., Oreland, L., Ruchkin, V. V., \& Grigorenko, E. L. (2008). Association between Polymorphisms in the Dopamine Transporter Gene and Depression: Evidence for a Gene-Environment Interaction in a Sample of Juvenile Detainees. Psychological Science, 19, 62-69. https://doi.org/10.1111/j.1467-9280.2008.02047.x

Hollingworth, S. A., Burgess, P. M., \& Whiteford, H. A. (2010). Affective and Anxiety Disorders: Prevalence, Treatment and Antidepressant Medication Use. Australian \& New Zealand Journal of Psychiatry, 44, 513-519.

Ivanova, J. I., Bienfait-Beuzon, C., Birnbaum, H. G., Connolly, C., Emani, S., \& Sheehy, M. (2011). Physicians' Decisions to Prescribe Antidepressant Therapy in Older Patients with Depression in a US Managed Care Plan. Drugs and Aging, 28, 51-62. https://doi.org/10.2165/11539900-000000000-00000

Kendler, K. S., Gatz, M., Gardner, C. O., \& Pedersen, N. L. (2006). A Swedish National Twin Study of Lifetime Major Depression. The American Journal of Psychiatry, 163, 109-114. https://doi.org/10.1176/appi.ajp.163.1.109

Kessler, R. C., Berglund, P., Demler, O., Jin, R., Koretz, D., Merikangas, K. R., Rush, A. J., Walters, E. E., \& Wang, P. S. (2003). National Comorbidity Survey Replication. The Epidemiology of Major Depressive Disorder: Results from the National Comorbidity Survey Replication (NCS-R). JAMA, 289, 3095-3105.

https://doi.org/10.1001/jama.289.23.3095

Khan, A., Faucett, J., Lichtenberg, P., Kirsch, I., \& Brown, W. A. (2012). A Systematic Review of Comparative Efficacy of Treatments and Controls for Depression. PLOS ONE, 7, e41778. https://doi.org/10.1371/journal.pone.0041778

Konarski, J. Z., McIntyre, R. S., Grupp, L. A., \& Kennedy, S. H. (2005). Is the Cerebellum Relevant in the Circuitry of Neuropsychiatric Disorders? Journal of Psychiatry \& Neuroscience, 30, 178-186. http://jpn.ca/vol30-issue3/30-3-178/

Kuehner, C. (2003). Gender Differences in Unipolar Depression: An Update of Epidemiological Findings and Possible Explanations. Acta Psychiatrica Scandinavica, 108, 163 174. https://doi.org/10.1034/j.1600-0447.2003.00204.x

Memon, A., \& Patel, K. (2013). Drug Use Pattern of Antidepressant Agents in Psychiatric Patients-A Prospective Study. NHL Journal of Medical Sciences, 2, 33-36.

Moore, M., Yuen, H., Dunn, N., Mulee, M., Maskell, J., \& Kendrick, T. (2009). Explaining the Rise in Antidepressant Prescribing: A Descriptive Study Using the General Practice Research Database. BMJ, 339, b3999. https://doi.org/10.1136/bmj.b3999

Murphy, J. M., Laird, N. M., Monson, R. R., Sobol, A. M., \& Leighton, A. H. (2000). A 40-Year Perspective on the Prevalence of Depression: The Stirling County Study. Arch Gen Psychiatry, 57, 209-215. https://doi.org/10.1001/archpsyc.57.3.209 
NICE (2005). Guidelines: Depression in Children and Adolescents (p. 5). London.

Rickards, H. (2005). Depression in Neurcological Disorders: Parkinson's Disease, Multiple Sclerosis, and Stroke. Journal of Neurology, Neurosurgery \& Psychiatry, 76, 48-52. https://doi.org/10.1136/jnnp.2004.060426

Rustad, J. K., Stern, T. A., Hebert, K. A., \& Musselman, D. L. (2013). Diagnosis and Treatment of Depression in Patients with Congestive Heart Failure: A Review of the Literature. The Primary Care Companion for CNS Disorders, 15, pii: PCC.13r01511.

Schmahmann, J. D. (2004). Disorders of the Cerebellum: Ataxia, Dysmetria of Thought, and the Cerebellar Cognitive Affective Syndrome. The Journal of Neuropsychiatry \& Clinical Neurosciences, 16, 367-378. https://doi.org/10.1176/jnp.16.3.367

Schmahmann, J. D., Weilburg, J. B., \& Sherman, J. C. (2007). The Neuropsychiatry of the Cerebellum-Insights from the Clinic. Cerebellum, 6, 254-267. https://doi.org/10.1080/14734220701490995

Schuckit, M. A., Tipp, J. E., Bergman, M., Reich, W., Hesselbrock, V. M., \& Smith, T. L. (1997). Comparison of Induced and Independent Major Depressive Disorders in 2945 Alcoholics. The American Journal of Psychiatry, 154, 948-957. https://doi.org/10.1176/ajp.154.7.948

Sim, K., Lee, N. B., Chua, H. C., Mahendran, R., Fujii, S., \& Yang, S. Y. (2007). Newer Antidepressant Drug Use in East Asian Psychiatric Treatment Settings: REAP (Research on East Asia Psychotropic Prescriptions) Study. British Journal of Clinical Pharmacology, 63, 431-437. https://doi.org/10.1111/j.1365-2125.2006.02780.x

Slavich, G. M. (2004). Deconstructing Depression: A Diathesis-Stress Perspective (Opinion). APS Observer.

Uchida, N., Chong, M. Y., Tan. C. H., Nagai, H., Tanaka, M., Lee, M. S. et al. (2007) International Study on Antidepressant Prescription Pattern at 20 Teaching Hospitals and Major Psychiatric Institutions in East Asia: Analysis of 1898 Cases from China, Japan, Korea, Singapore and Taiwan. Psychiatry and Clinical Neurosciences, 61, 522-528.

US Department of Health and Human Services (1999). Fundamentals of Mental Health and Mental Illness.

Van Praag, H. (1987). Monoamine Precursors in Depression: Present State and Prospects. In J. Zohar, \& R. H. Belmaker (Eds.), Treating Resistant Depression (pp. 279-306). New York: PMA Publishing.

Vos, T. et al. (2012). Years Lived with Disability (YLDs) for 1160 Sequelae of 289 Diseases and Injuries 1990-2010: A Systematic Analysis for the Global Burden of Disease Study 2010. The Lancet, 380, 2163-2196. https://doi.org/10.1016/S0140-6736(12)61729-2

Wakefield, J. C., Schmitz, M. F., First, M. B., \& Horwitz, A. V. (2007). Extending the Bereavement Exclusion for Major Depression to Other Losses: Evidence from the National Comorbidity Survey. Arch Gen Psychiatry, 64, 433-440. https://doi.org/10.1001/archpsyc.64.4.433

Zhang, Y., Becker, T., \& Kösters, M. (2013). Preliminary Study of Patterns of Medication Use for Depression Treatment in China. Asia-Pacific Psychiatry, 5, 231-236.

https://doi.org/10.1111/appy.12022 
Submit or recommend next manuscript to SCIRP and we will provide best service for you:

Accepting pre-submission inquiries through Email, Facebook, LinkedIn, Twitter, etc. A wide selection of journals (inclusive of 9 subjects, more than 200 journals)

Providing 24-hour high-quality service

User-friendly online submission system

Fair and swift peer-review system

Efficient typesetting and proofreading procedure

Display of the result of downloads and visits, as well as the number of cited articles Maximum dissemination of your research work

Submit your manuscript at: http://papersubmission.scirp.org/

Or contact ojd@scirp.org 